\title{
Evaluation of Power Management Strategy for Renewable Microgrid System
}

\author{
Krishan Kumar, M. A. Ansari \\ Electrical Engineering Departement, Gautam Buddha University, India
}

\begin{tabular}{l}
\hline \hline Article Info \\
\hline Article history: \\
Received Apr 16, 2018 \\
Revised Apr 26, 2018 \\
Accepted May 6, 2018 \\
\hline
\end{tabular}

\section{Keyword:}

Fuel cell

Microgrid system

Power management

Solar photovoltaic

Wind turbine generator

\begin{abstract}
This paper presents the evaluation and control of renewable energy sources based micro-grid system having solar photovoltaic, wind turbine generator, fuel cell and diesel engine generator. A battery storage system has also been installed to provide unintrupted power supply and to store excess power. The proposed micro-grid system is simulated on Matlab/Simulink software and the performance has been analysied with two cases considering different environmental conditions to check the optimal performance of the system. In the first case, the solar photovoltaic, fuel cell, diesel engine generator and battery storage system has been considered and in the second case, the solar photovoltaic source is replaced by the wind turbines. For both the cases, simulation has been done for 300 seconds to findout the optimal fulfilment of the demand. The time domain analysis has been done by varying the solar irradiance and wind speed in respective cases to check the system performance. This work shows the efficient control of various distributed energy resources in the micro-grid system and meeting the load demand efficiently.
\end{abstract}

Copyright $\odot 2018$ Institute of Advanced Engineering and Science. All rights reserved.

\section{Corresponding Author:}

Krishan Kumar,

Electrical Engineering Departement, Gautam Buddha University,

Gr. Noida-201312, India

Email: tyagi315@gmail.com

\section{INTRODUCTION}

The energy prototype is changing throughout the world from conventional energy sources to the renewable energy sources (RES) as they have potential to handle the major challenges related to energy. Although, high investment cost is a major hurdle to develop these micro-grid systems still this is an advantageous for developing countries for off-grid power generation with no negative impact to the environment [1]. The RES based micro-grid (MG) system incorporates more than one type of energy sources. Appropriate combination of different types of energy sources can be used for rural electrification creating a modern micro-grid system. Availability of fuel, location and the installation cost are some of the major factors which determines the effectiveness of stand-alone micro-grid system [2]. The concept of MG system is very useful as the active power losses can be reduced easily by which the generation cost can be minimized and the voltage profile can also be maintained [3], [4].

Utilization of RES such as solar photovoltaic (PV) and wind turbine generator (WTG) offers environmental benefits while providing sustainable power generation for industrial and domestic usage. Now a day's more emphasis is given to wind and solar energy systems as sun light and wind is free, abundant and clean. However, interconnection of these sources to the micro-grids requires a sophisticated power management control for their proper utilization. Furthermore, the non-linear behaviour of the solar and wind energy systems along with the changing environmental conditions increases the complexity of the system [5].

Along with the known advantages of solar energy, the PV system neither produces any noise nor does have any moving part and so requires less maintenance but solar panels are not very efficient. At 
present, they have only about $20-25 \%$ efficiency of converting electrical energy from sunlight [6,7]. It is estimated that nearly $2 \%$ of the solar energy that falls on earth is turned into wind, because of the uneven heating of the surface of earth. Wind energy can also be converted into electrical energy by means of wind generators. Freely available wind, high energy conversion efficiency and eco-friendly energy conversion are the main merits of wind energy conversion system but these systems are noisy and requires regular maintenance [8], [9].

Fuel cell (FC) is another emerging renewable energy source with high energy conversion efficiency. Nowadays, FC with natural fuel or hydrogen is getting more attention from the researchers. It can be used at homes, hospitals, industries and now finding their use in electrical vehicles also [10]. Usually, batteries are used in conjunction with the micro-grids as an energy storage system to provide the supply at the time of scarcity of supply from the RES. Diesel generators are also included in these MGs to supply energy in case of unavailability from other sources [11].

In this work, analysis of RES as discussed above for MG system is carried out with the help of a developed Matlab/Simulink model. The paper is divided in five section. Section I includes the elementary part of the MG and power management system. Section II describes the micro-grid system configuration. Section III presents the transfer function derivation of various sub systems while section IV describes the control methodology and in Section $\mathrm{V}$, results and the conclusion is discussed.

\section{MICROGRID CONFIGURATION}

The configuration of micro-grid system under investigation is shown in Figure 1. The MG system under investigation consists of three wind turbines, one solar PV system, two fuel cells (FC), one diesel engine generator (DEG) and one battery storage system (BSS) [12-14]. Figure 1 illustrates the major supply sources considered for the system.

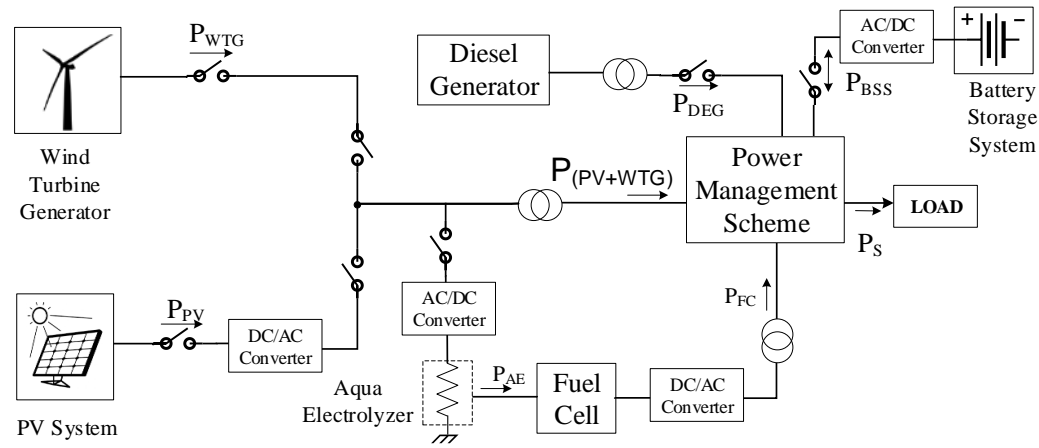

Figure 1. Proposed microgrid system configuration

\subsection{Wind Energy System}

Doubly fed induction generator (DFIG) is commonly used with pitch controlled variable speed wind turbine. The DFIG is preferred because of less maintenance requirement, less power fluctuations, good power quality and high efficiency [9], [15].

Mathematically, mechanical power output of wind turbine can be expressed as:

$$
P_{m}=0.5 \rho_{\text {air }} A_{w} \cdot P_{c}(\lambda, \beta) \cdot v_{w t}^{3}
$$

Where, power coefficient can be given as [5]:

$$
P_{c}(\lambda, \beta)=0.5176\left(\left(\frac{116}{\lambda+0.08 \beta}-\frac{4.06}{\beta^{3}+1}\right)-0.4 \beta-5\right) e^{\frac{21}{\lambda}}+0.0068 \lambda
$$

Where, $P_{m}$ is mechanical power, $\rho_{\text {air }}$ is air density $\left(\mathrm{kg} / \mathrm{m}^{3}\right), A_{w}$ is swept area of wind turbine, $v_{w t}$ is wind speed $(\mathrm{m} / \mathrm{s}), P_{c}$ is power coefficient, $\lambda$ is tip speed ratio and $\beta$ is blade pitch angle.

Dynamic electromechanical equations of wind turbine shaft consisting of generator mass and wind turbine mass can be given as 


$$
\begin{aligned}
& \tau_{w t}=I_{w t} \frac{d \omega_{w t}}{d t}+D_{w t}\left(\omega_{w t}-\omega_{g}\right)+S_{w t}\left(\theta_{w t}-\theta_{g}\right) \\
& \frac{d \theta_{w t}}{d t}=\omega_{w t} \\
& -\tau_{g}=I_{g} \frac{d \omega_{g}}{d t}+D_{g}\left(\omega_{g}-\omega_{w t}\right)+S_{g}\left(\theta_{g}-\theta_{w t}\right) \\
& \frac{d \theta_{g}}{d t}=\omega_{g}
\end{aligned}
$$

Where, $\omega_{w t}$ is turbine rotational speed $(\mathrm{rad} / \mathrm{s}), \omega_{g}$ is generator rotational speed $(\mathrm{rad} / \mathrm{s}), \theta_{w t}$ is turbine angular position (rad), $\theta_{g}$ is turbine rotational position (rad), $\tau_{w t}$ is turbine torque respectively, $\tau_{g}$ is generator torque respectively, $I_{w t}$ is turbine moment of inertia, $I_{g}$ is generator moment of inertia, $D_{w t}$ is turbine linear damping coefficient, $D_{g}$ is generator linear damping coefficient, $S_{w t}$ is turbine stiffness coefficient and $S_{g}$ is generator stiffness coefficient.

\subsection{Solar PV System}

The general configuration of solar PV system is shown in Figure 2. It generally consists of a PV source, converter and load. Single-diode equivalent circuit shown in Figure 3 can be used for modelling the solar PV cell behaviour [16].

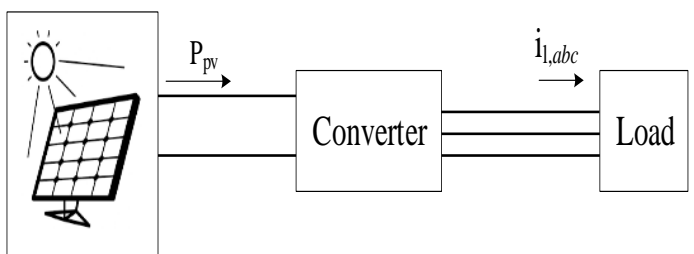

Figure 2. Configuration of solar PV system

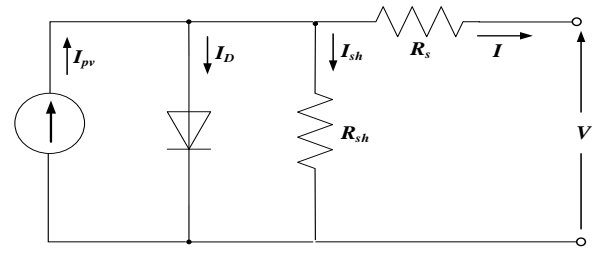

Figure 3. Single diode equivalent circuit of solar cell [16]

The basic governing equations of PV cell current are given as:

$$
\begin{aligned}
& I=I_{p v}-I_{D}-I_{s h} \\
& I=I_{p v}-I_{s}\left(e^{\frac{q\left(V+I R_{s}\right)}{A_{i} k T}}-1\right)-\frac{V+I R_{s}}{R_{s h}}
\end{aligned}
$$

Where, $I_{p v}$ is photocurrent, $I_{D}$ is diode current, $I_{s}$ is diode saturation current, $I_{s h}$ is shunt current, $I$ is output current, $V$ is output voltage, $k$ is Boltzman's constant, $q$ is charge on electron, $T$ is absolute temperature $\left({ }^{\circ} \mathrm{K}\right)$ of cell, $A_{i}$ is ideality factor of p-n junction, $R_{s}$ is series resistor and $R_{s h}$ is shunt resistor.

The output power (in Watts) of photovoltaic system is given by:

$$
P_{P V}=\eta A \phi\left[1-0.005\left(T_{a}+25\right)\right]
$$

Where, $\eta$ is conversion efficiency of $\mathrm{PV}$ system, $A$ is area of $\mathrm{PV}$ array, $\phi$ is solar radiation and $T_{a}$ is ambient temperature in ${ }^{\circ} \mathrm{C}$. 


\subsection{Fuel Cell}

A general structure of FC consists of an electrolyte as its main part which is covered with water and fuel at surroundings as shown in Figure 4 below.

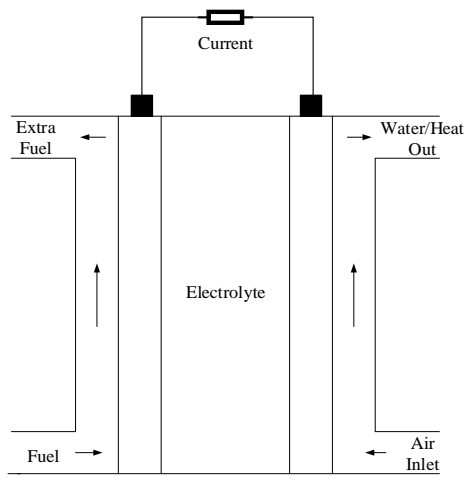

Figure 4. Structure of fuel cell power unit

The fuel cell produces small amount of output power so, it is very important to increase the level of voltage at the output terminals of fuel cell. Therefore, a boost converter is connected at the output terminals of fuel cell in stand-alone system [17].

The expression of terminal voltage for a single FC can be expressed as:

$$
V_{\text {cell }}=E_{t}+V_{a}+V_{\text {ohm }}+V_{\text {con }}
$$

Where, $V_{\text {cell }}$ is voltage of FC, $E_{t}$ is thermodynamic potential of the cell, $V_{a}$ is activation over potential, $V_{\text {ohm }}$ is ohmic over potential measures, $V_{c o n}$ is concentration over potential.

$E_{t}$ also known as the open circuit voltage of the FC representing the potential of the cell without load and can be given as [15]:

$$
E_{t}=\frac{\Delta G}{2 F}+\frac{\Delta S}{2 F}\left(T-T_{\text {ref }}\right)+\frac{R T}{2 F}\left[\ln \left(P_{H_{2}}\right)+\frac{1}{2} \ln \left(P_{o_{2}}\right)\right]
$$

Where, $\Delta G$ is change of free Gibbs energy $(\mathrm{J} / \mathrm{mol}), \Delta S$ is change of the entropy $(\mathrm{J} / \mathrm{mol}), R$ is universal constant of the gases $(8.314 \mathrm{~J} / \mathrm{K} \mathrm{mol}), P_{\mathrm{H} 2}$ is partial pressures of hydrogen $(\mathrm{atm}), P_{\mathrm{O} 2}$ is partial pressures of oxygen $(\mathrm{atm}), T$ operation temperature $\left({ }^{\circ} \mathrm{K}\right)$ of the cell, $T_{\text {ref }}$ reference temperature.

The activation over potential, including anode and cathode, can be given by [17]:

$$
V_{a}=-\left[\xi_{1}+\xi_{2} T+\xi_{3} T \ln \left(\mathrm{CO}_{2}\right)+\xi_{4} T \ln \left(i_{F C}\right)\right]
$$

Where, $i_{F C}$ is cell operating current and $\xi_{1}, \xi_{2}, \xi_{3}$ and $\xi_{4}$ represent parametric coefficients for different types of cells. These are dependent on the kinetic energy, thermodynamic potential and electrochemical structure of the fuel cell.

The ohmic over potential can be expressed as:

$$
V_{\text {ohm }}=i_{F C} \times\left(R_{M}+R_{C}\right)
$$

The drop in voltage due to the mass transportation can be given by:

$$
V_{\text {con }}=-B \ln \left(1-\frac{J}{J_{\max }}\right)
$$

Where, $R_{M}$ is equivalent resistor of the electrolyte, $R_{C}$ is resistance offered to the flow of protons through the electrolyte, $B$ is parametric coefficient, $J$ is actual current density of FC in $A / \mathrm{cm}^{2}, J_{\max }$ is maximum current density of FC in $A / \mathrm{cm}^{2}$. 


\section{TRANSFER FUNCTION OF VARIOUS SUBSYSTEMS OF MG}

In this paper, the dynamic models of various distributed energy resources (DER) units are approximated by first order linear model [18-19] and are given as below:

Transfer function of solar power generator is given as:

$$
H_{P V}(s)=\frac{K_{P V}}{1+s T_{P V}}=\frac{\Delta P_{P V}}{\Delta \phi}
$$

Where, $K_{P V}$ is gain constant of solar PV and $T_{P V}$ is time constant of solar PV.

Transfer function of wind turbine generator is given as:

$$
H_{W T G}(s)=\frac{K_{W T G}}{1+s T_{W T G}}=\frac{\Delta P_{W T G k}}{\Delta P_{m}}, k=1,2,3
$$

Where, $K_{W T G}$ is gain constant of wind turbine (WT), $T_{W T G}$ is time constant of WT, $P_{W T G}$ is output power from WT and $P_{m}$ is mechanical power output from wind turbine.

Transfer function of fuel cell is given as

$$
H_{F C k}(s)=\frac{K_{F C}}{1+s T_{F C}}=\frac{\Delta P_{F C k}}{\Delta P_{A E}}, k=1,2
$$

Where, $K_{F C}$ is gain constant of fuel cell (FC), $T_{F C}$ is time constant of FC, $P_{F C}$ is output power from FC, $P_{A E}$ is output from aqua electrolyzer (AE).

Transfer function of diesel engine generator is given as:

$$
H_{D E G}(s)=\frac{K_{D E G}}{1+s T_{D E G}}=\frac{\Delta P_{D E G}}{\Delta f}
$$

Where, KDEG is gain constant of diesel engine generator (DEG), TDEG is time constant of DEG, PDEG is output power from DEG and $\mathrm{f}$ is frequency.

Transfer function of aqua electrolyzer which works as exciter to the FC is given as:

$$
\begin{aligned}
& H_{A E}(s)=\frac{K_{A E}}{1+s T_{A E}}=\frac{\Delta P_{A E}}{\Delta P_{W T G}\left(1-K_{n}\right)} \\
& \text { or } \frac{\Delta P_{A E}}{\Delta P_{P V}\left(1-K_{n}\right)}
\end{aligned}
$$

Where, $K_{A E}$ is gain constant of $\mathrm{AE}, T_{A E}$ is time constant of $\mathrm{AE}, P_{A E}$ is output power from $\mathrm{AE}$, $K_{n}$ is constant; $\frac{P_{t}}{P_{P V}}$ or $\frac{P_{t}}{P_{W T G}}, P_{t}$ is constant; $\left(P_{P V}-P_{A E}\right)$ or $\left(P_{W T G}-P_{A E}\right)$.

Transfer function of battery storage system is given as:

$$
H_{B S S}(s)=\frac{K_{B S S}}{1+s T_{B S S}}=\frac{\Delta P_{B S S}}{\Delta f}
$$

Where, $K_{B S S}$ is gain constant of battery storage system (BSS), $T_{B S S}$ is time constant of BSS, $P_{B S S}$ is output power from BSS and $P_{s}$ is supply power, $P_{(P V+W T G)}$ is combination of PV and WTG power.

The transfer functions of different DER units of the MG system under consideration [5] are given in above equations from 15 to 20 . 


\section{POWER MANAGEMENT STRATEGY}

The main aim of this work is to manage the power from different DER units in a MG system to cater/meet the load demand. The working of proposed MG system is divided into two cases. In the first case of the system, proposed MG model consists of three sources of power generation and one storage system namely solar system, fuel cell, battery storage system and diesel engine generator [20]. The control scheme for this section can be understood with the help of a flow chart given as in Figure 5. The steps of the flow chart for control scheme of MG system are given as follows:

Step 1: Check if power is generated by PV or not.

Step 2: If yes, PV supplies to AE and it enables FC, both PV and FC will supply to load.

Step 3: Check supply power and demand power and go to next step.

Step 4: If supply more than demand, battery charges.

Step 5: Check the battery SOC (State of Charge) is high or less than minimum.

Step 6: If high, then PV, FC and battery supplies power to load.

Step 7: If less, then DEG will start.

Step 8: Now, DEG, PV and FC will supply the load.

Step 9: If the supply meets the load demand, then

Step 10: Process Ends.

Step 11: Else, the process repeats till the demand is met.

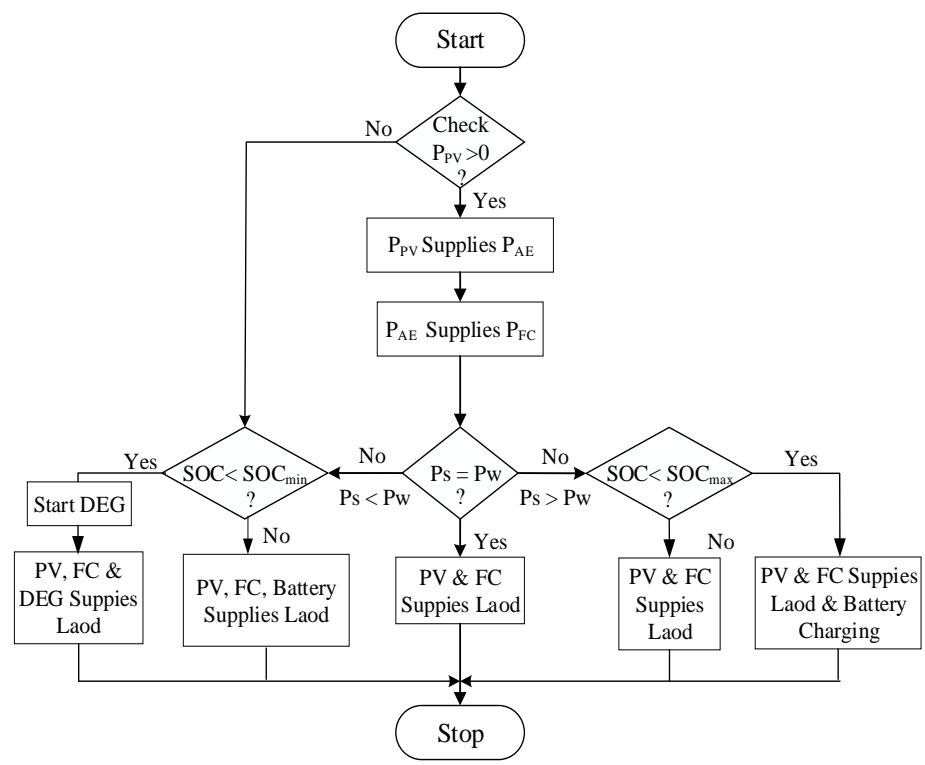

Figure 5. Flow chart of control scheme for case-I of proposed MG structure for solar PV

In the second part of the proposed MG model, it also consists of three sources of power generation and one storage system namely WT, FC, battery storage system and DEG. The control scheme for this section can be understand with the help of flow chart shown in Figure 6. The steps of flow chart for control scheme of MG are as follows:

Step 1: Check if power is generated by WT or not.

Step 2: If yes, WT supplies to AE and it enables FC, both WT and FC will supply to load.

Step 3: Check supply power and demand power, go to next step.

Step 4: If supply more than demand, battery charges.

Step 5: Check the battery SOC is high or less than minimum.

Step 6: If high, then WT, FC and battery supplies the load.

Step 7: If less, then DEG will start.

Step 8: Now, DEG, WT and FC will supply the load.

Step 9: If the supply meets the load demand, than

Step 10: Process Ends.

Step 11: Else, the process repeats. 


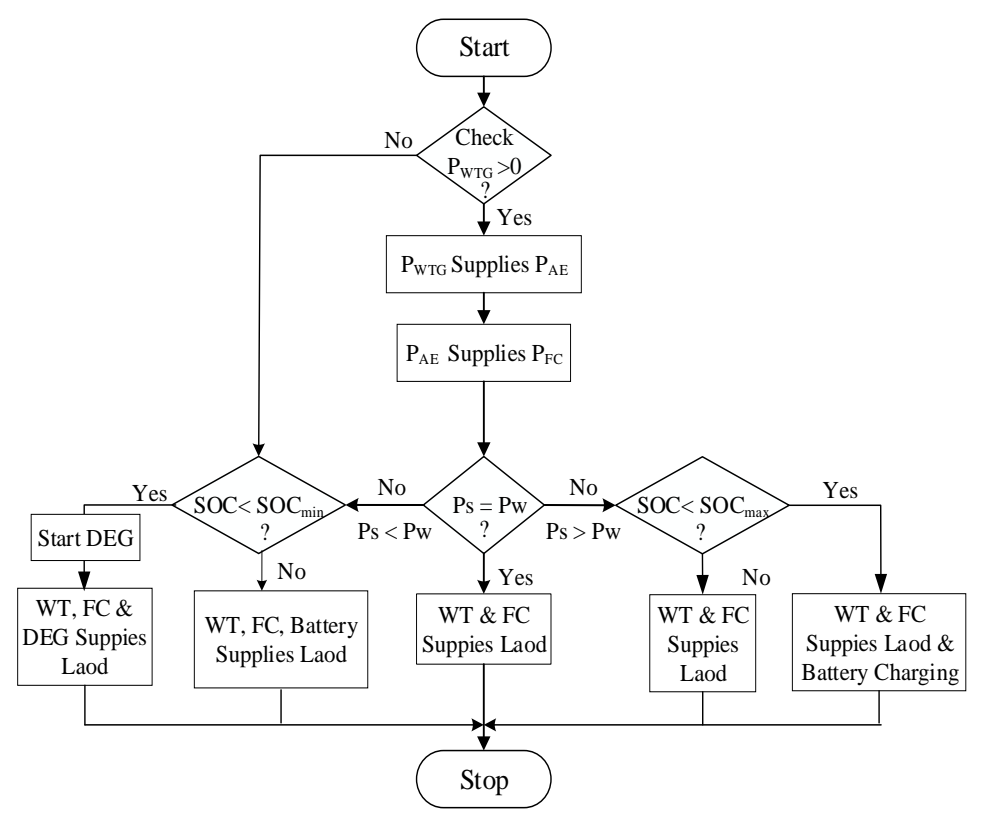

Figure 6. Flow chart of control scheme for case-II of proposed MG structure for WT

Now, with the help of these control schemes as shown in figure 5 and figure 6 , the power management schemes are applied. The two cases i.e. case I and case II of proposed MG structures are discussed in next section of results and discussion where the control scheme for both the cases is explained with results.

\section{RESULTS AND DISCUSSION}

The different arrangements of proposed microgrid system have been considered here which consist of combination of three WT, one solar PV system, two FC, BSS and one diesel engine generator.

The two configurations of MG systems are simulated. In first case, the solar PV, FC, DEG and battery storage system as shown in figure 7 are considered. In second case, WT, FC, DEG and battery storage system as shown in figure 15 are considered.

Case I: This case shows the time domain analysis of the system consists PV, FC, DEG and battery storage system. Figure 7 shows the block diagram of the system. The time domain analysis is divided into different slots of time for 300 seconds. Figures 8-13 shows the p.u. power of supply and demand, PV, DEG, $\mathrm{AE}, \mathrm{FC}$ and battery storage system respectively. Figure 14 shows the frequency deviation.

a. $\quad 0 \mathrm{~s}<\mathrm{t} \leq 25 \mathrm{~s}$ : Irradiation is low, therefore, power generated by PV is less than 0.5 p.u., it varies according to irradiation. If $P_{p v}$ is less than 1.0 p.u. i.e. supplied power $\left(P_{s}\right)$, DEG will start to generate the power to fulfill the demand, a smaller part of PV is sent to AE which will generate available power to FC. The power generated from FC is 0.22 p.u., if supply $\left(P_{s}\right)$ is greater than demand $\left(P_{w}\right)$ than the energy will be stored to battery storage system.

b. $25 \mathrm{~s}<\mathrm{t} \leq 75 \mathrm{~s}$ : Irradiation is below 0.2 p.u. at $\mathrm{t}=25 \mathrm{sec}$. and solar power is also 0.2 p.u. and FC power is 0.17 p.u., now to meet the demand the DEG, battery storage system and FC increased. The frequency deviation is still less than zero because supply is less than demand.

c. $75 \mathrm{~s}<\mathrm{t} \leq 200 \mathrm{~s}$ : Now, irradiation increasing linearly. So, solar PV, AE and FC also increase linearly. To meet the demand DEG and battery energy storage decreases linearly. The frequency deviation is about to zero because irradiation and solar PV increases linearly.

d. $200 \mathrm{~s}<\mathrm{t} \leq 250 \mathrm{~s}$ : During this period, demand power suddenly decreases from 1.0 p.u. to 0.5 p.u., now DEG also goes to 0.1 p.u. and battery storage system charged, since the $P_{s}$ is closer to $P_{w}$, frequency deviation approaches near to zero.

e. $250 \mathrm{~s}<\mathrm{t} \leq 300 \mathrm{~s}$ : During this period demand again suddenly increase from 0.5 p.u. to 1.0 p.u., as irradiation is decreasing linearly, so, solar PV, AE and AE also decrease linearly. Diesel engine generator rises to 0.22 p.u., since $P_{s}$ is marginally lower than to $P_{w}$, frequency deviation goes near to zero but negative. 


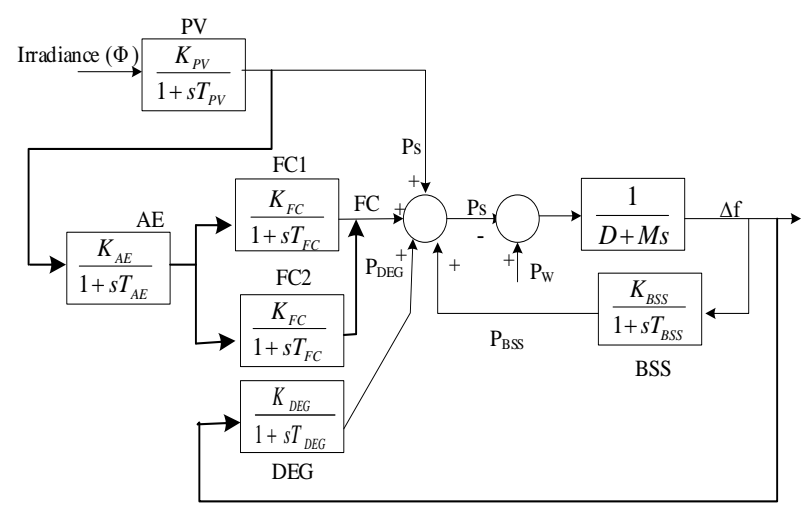

Figure 7. Block diagram of MG system for solar PV (Case I)

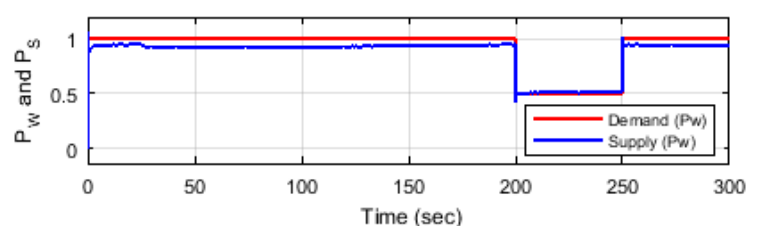

Figure 8. Supplied power (Ps) and demand power (Pw) by microgrid

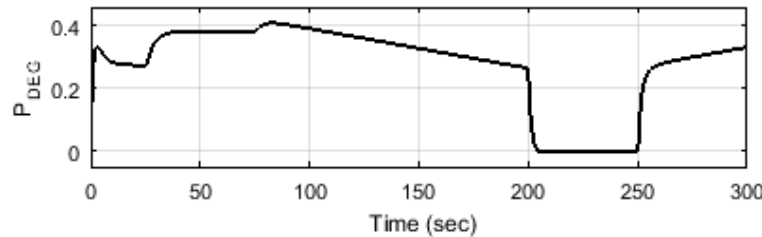

Figure 10. Output power from diesel engine generator

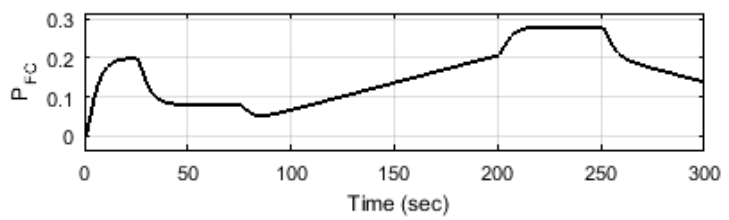

Figure 12. Output power from fuel cell

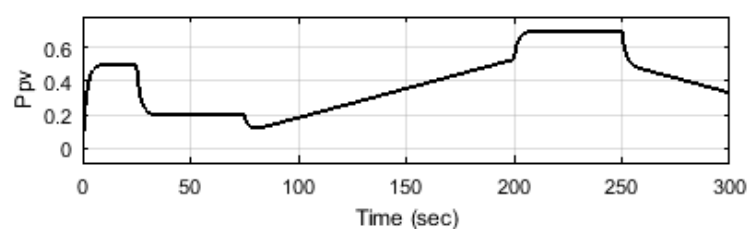

Figure 9. Output power from solar PV

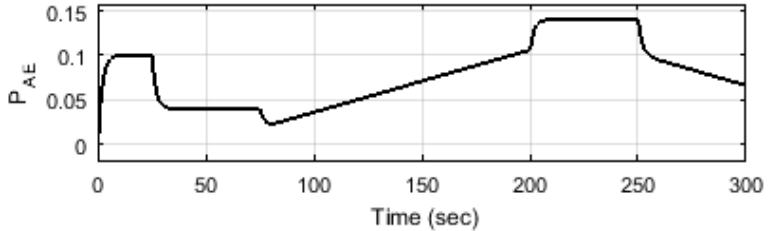

Figure 11. Output power of aqua electrolyzer

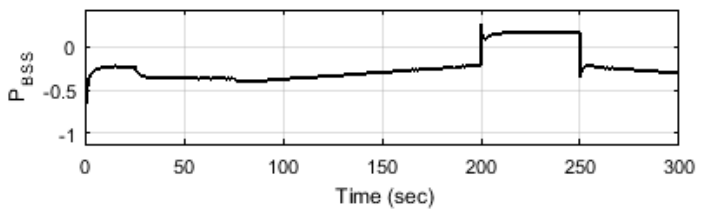

Figure 13 . Battery charging and discharging

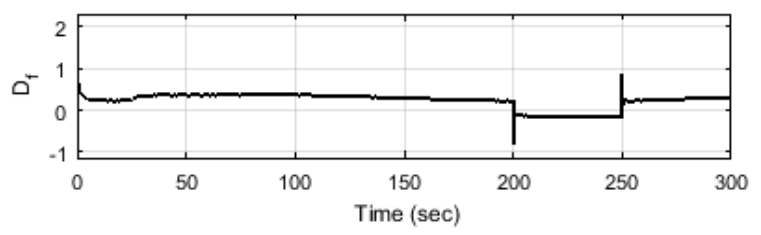

Figure 14. Deviation in frequency 
Case II: This case shows the time domain analysis of the system consists WT, FC, DEG and battery storage system (BSS). Figure 15 shows the block diagram of the system. Here, also the time domain analysis is divided into different slots of time for 300 seconds. Figures 16-21 shows the p.u. power of supply and demand, WT, DEG, AE, FC and battery storage system respectively. Figure 22 shows the frequency deviation.

a. $\quad 0 \mathrm{~s}<\mathrm{t} \leq 50 \mathrm{~s}$ : In this section the wind speed is $7.5 \mathrm{~m} / \mathrm{s}$, and power generated by WT is below 0.3 p.u., a very less amount of WT power is sent to AE which will energies the FC. The DEG is also connected to system at $\mathrm{t}=0 \mathrm{~s}$, which generates power 0.9 p.u., because of less power generation by WT energy will not be stored to battery storage system. Frequency deviation varied around zero.

b. $\quad 50 \mathrm{~s}<\mathrm{t} \leq 100 \mathrm{~s}$ : In this section the wind speed is $7.5 \mathrm{~m} / \mathrm{s}$, demand changes from 1.0 to 0.5 p.u., simultaneously DEG unit also goes from 0.9 to 0.4 p.u. for balancing demand and supply. Frequency deviation increases slightly higher because power generation is slightly higher than demand.

c. $\quad 100 \mathrm{~s}<\mathrm{t} \leq 200 \mathrm{~s}$ : The wind speed is still not changing i.e. $7.5 \mathrm{~m} / \mathrm{s}$, demand changes from 0.5 to 1.0 p.u., now system behave same as $0 \mathrm{~s}<\mathrm{t}<50 \mathrm{~s}$.

d. $200 \mathrm{~s}<\mathrm{t} \leq 250 \mathrm{~s}$ : In this section, speed of wind suddenly goes very low. So, WT, AE and FC also decrease to zero. Demand is still 1.0 p.u., now DEG and battery storage system supplying to meeting the demand. Frequency deviation approaches to zero.

e. $\quad 250 \mathrm{~s}<\mathrm{t} \leq 300 \mathrm{~s}$ : In this section, wind speed rises to $15 \mathrm{~m} / \mathrm{s}$. Now the wind turbine power is 1.0 p.u., which is almost equal to demand, a small part of WT power is sent to AE to produce FC power which is 0.2 p.u., now the generation is more than demand so the extra power generated will store in battery storage system. Here, WT generates enough power so DEG will disconnected. Frequency deviation approaches to zero here.

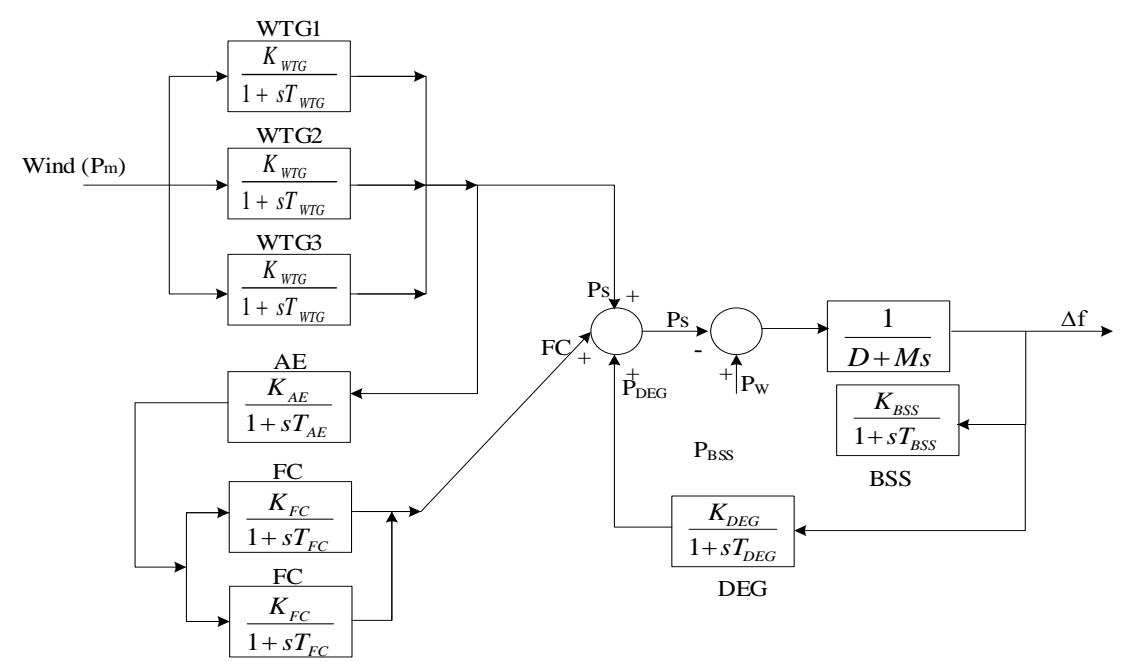

Figure 15. Block diagram of MG system for WT (Case II)

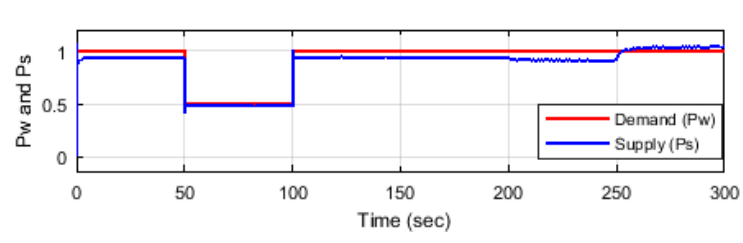

Figure 16. Supplied power (Ps) and demand power (Pw) by microgrid

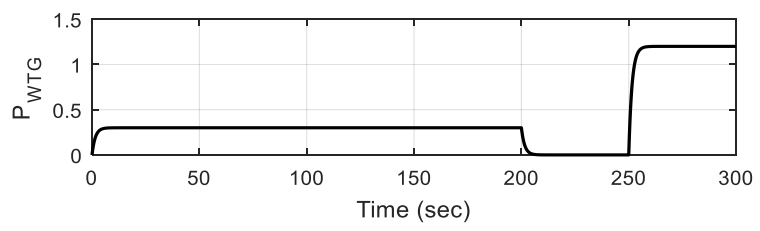

Figure 17. Output power from wind turbine 


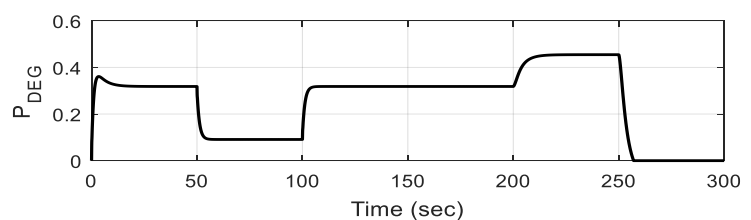

Figure 18. Output power from diesel engine generator

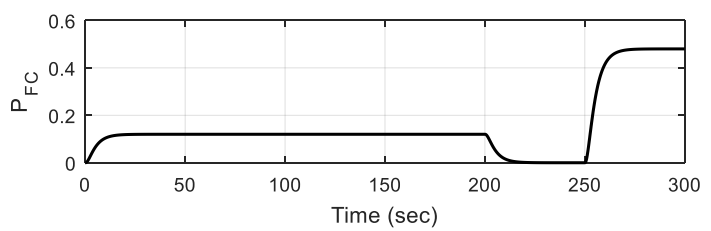

Figure 20. Output power from fuel cell

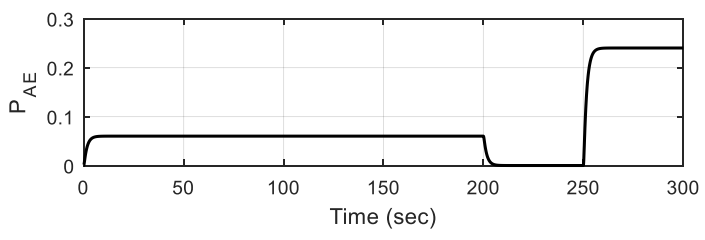

Figure 19. Output power of aqua electrolyzer

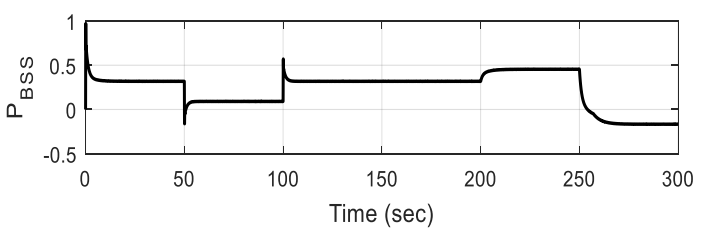

Figure 21. Battery charging and discharging

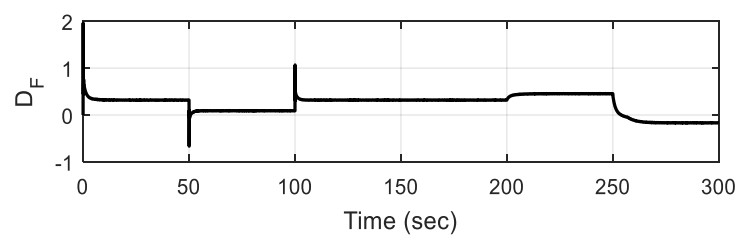

Figure 22. Deviation in frequency

Form the obtained results, it is clear that the frequency deviation is more controlled and near to zero with our proposed model. The battery storage system is also much effective by which the efficient powerfrequency balance is achieved as compared to other work [8]. Proposed technique is simple and easy to implement as compared to the other techniques for the analysis purpose of MG system studied in literature [5], [21].

\section{CONCLUSION}

The performance evaluation and control of MG system with different renewable energy sources operating in various environmental conditions has been carried out in this work. First order approximated mathematical model of each subsystem is derived for simplicity. The time domain analysis of MG system is divided in two cases. In both the cases, sudden drop and rise in wind speed, change in solar radiation has been considered with step changing of load demand. The system is working efficiently with different operating conditions which is divided into different time slots of 300 seconds. The battery storage system is working efficiently in this system, when the supply is more than demand, the BSS is charging and when supply is less than demand, the BSS is discharging or working as source. The diesel generator units are efficiently meeting the demand power when renewable energy sources are not available and BSS is also not charged. Now from the results and discussion, it can be concluded that the proposed system efficiently meets the load demand efficiently at various operating and environmental conditions. The proposed system may be very useful in remote locations for small MGs and for the locations where abudent natural source of energy (wind and solar) is available.

\section{REFERENCES}

[1] M. Zachar and P. Daoutidis. Microgrid/Macrogrid Energy Exchange: A Novel Market Structure and Stochastic Scheduling. IEEE Transactions on Smart Grid. 2017; 8(1): 178-189.

[2] I. Aldaouab, M. Daniels and K. Hallinan. Microgrid cost optimization for a mixed-use building. IEEE Texas Power and Energy Conference (TPEC). College Station. TX. 2017: 1-5. 
[3] Ganiyu Adedayo Ajenikoko, Olakunle ad Elijah Olabode. Optimal Power Flow with Reactive Power Compensation for Cost and Loss Minimization on Nigerian Power Grid System. Indonesian Journal of Electrical Engineering and Informatics. 2017; 5(2): 236-247.

[4] A. Maknouninejad and Z. Qu. Realizing Unified Microgrid Voltage Profile and Loss Minimization: A Cooperative Distributed Optimization and Control Approach. IEEE Transactions on Smart Grid. 2014; 5(4): 1621-1630.

[5] D. J. Lee and L. Wang. Small-Signal Stability Analysis of an Autonomous Hybrid Renewable Energy Power Generation/Energy Storage System Part I: Time-Domain Simulations. IEEE Transactions on Energy Conversion. 2008; 23(1): 311-320.

[6] Vinay Rana, Y. K. Chauhan and M.A. Ansari. A Multi-level Inverter Fed Induction Motor Driven Water Pumping System Based on Solar Photovoltaic. IEEE India International Conference on Power Electrinics, Thapar University, Patiala, India. 2016: 1-5.

[7] A. Bennouk, A. Nejmi and M. Ramzi. A Lyapunov Based Approach to Enchance Wind Turbine Stability. Indonesian Journal of Electrical Engineering and Informatics. 2017; 5(2): 145-154.

[8] Karabiber, Abdulkerim, Cemal Keles, Asim Kaygusuz, and B. Baykant Alagoz. An approach for the integration of renewable distributed generation in hybrid DC/AC microgrids. Renewable Energy. 2013; 52: 251-259.

[9] Dida, Abdelhak, and Djilani Benattous. A complete modeling and simulation of DFIG based wind turbine system using fuzzy logic control. Frontiers in Energy. 2016; 10(2): 143-154.

[10] M. Jang, M. Ciobotaru and V. G. Agelidis. Design and Implementation of Digital Control in a Fuel Cell System. IEEE Trans. on Industrial Informatics. 2013; 9(2): 1158-1166.

[11] Krishan Kumar and M. A. Ansari. Mathematical Modeling and Simulation of Renewable Energy-based Microgrid System. Indian Journal of Industrial and Applied Mathematics. 2017; 8(2); 155-166.

[12] P. C. Sekhar and S. Mishra. Storage Free Smart Energy Management for Frequency Control in a Diesel-PV-Fuel Cell-Based Hybrid AC Microgrid. IEEE Transaction on Neural Networks and Learning Systems. 2016; 27(8): 1657-1671.

[13] C. Dou, M. Lv, T. Zhao, Y. Ji and H. Li. Decentralised coordinated control of microgrid based on multi-agent system. IET Generation, Transmission \& Distribution. 2015; 16(9): 2474-2484.

[14] Hassan, M. A., and M. A. Abido. Real time implementation and optimal design of autonomous microgrids. Electric Power Systems Research. 2014; 109: 118-127.

[15] T.L. Vandoorn, B. Renders, L. Degroote, B. Meersman, and L. Van- develde. Active load control in islanded microgrids based on the grid voltage. IEEE Transaction on Smart Grid. 2011; 2(1): 139-151.

[16] Ali Cheknane, Hikmat S. Hilal, Faycal Djeffal, Boumediène Benyoucef and Jean-Pierre Charles. An equivalent circuit approach to organic solar cell modelling. Microelectronics Journal. 2008; 39(10): 1173-1180.

[17] J. Correa, F. Farret, L. Canha and M. Simoes. An Electrochemical-Based Fuel-Cell Model Suitable for Electrical Engineering Automation Approach. IEEE Transaction on Ind. Electron. 2004; 51(5); 1103-1112.

[18] A. Ahadi, S. M. M. Aval, H. Hayati. Generating capacity adequacy evaluation of large-scale, grid-connected photovoltaic systems. Frontiers in Energy, 2016; 10(3): 308-318.

[19] Hogerwaard, Janette, Ibrahim Dincer, and Greg F. Naterer. Solar energy based integrated system for power generation, refrigeration and desalination. Applied Thermal Engineering. 2017; 121: 1059-1069.

[20] F. Ding, K.A. Loparo and C. Wang. Modeling and simulation of grid-connected hybrid AC/DC microgrid. IEEE power and energy society general meeting, San Diego. 2012: 1-8.

[21] M.S. Mahmoud, S. Azher Hussain and M.A. Abido. Modeling and control of microgrid an overview. Journal of the Franklin Institute. 2014; 351(5): 2822-2859.

\section{APPENDIXS}

Table 1. Micro-Grid System Parameters [5]

\begin{tabular}{cc}
\hline System & Parameters \\
\hline Solar PV system & $\mathrm{K}_{\mathrm{PV}}=1, \mathrm{~T}_{\mathrm{PV}}=1.8 \mathrm{sec}$. \\
Wind energy system & $\mathrm{K}_{\mathrm{WTG}}=1, \mathrm{~T}_{\mathrm{WTG}}=1.5 \mathrm{sec}$. \\
Fuel cell & $\mathrm{K}_{\mathrm{FC}}=0.01, \mathrm{~T}_{\mathrm{FC}}=4 \mathrm{sec}$. \\
Battery storage system & $\mathrm{K}_{\mathrm{BSS}}=0.0033, \mathrm{~T}_{\mathrm{BSS}}=0.1 \mathrm{sec}$. \\
Battery storage system & $\mathrm{K}_{\mathrm{DEG}}=0.0033, \mathrm{~T}_{\mathrm{DEG}}=2 \mathrm{sec}$. \\
Constants & $\mathrm{K}_{\mathrm{n}}=0.6, \mathrm{M}=0.2 \& \mathrm{D}=0.012$ \\
\hline
\end{tabular}

IJEEI, Vol. 6, No. 2, June 2018 : $132-142$ 